\title{
A device for simultaneously homogenizing numbers of individual small insects for electrophoresis
}

\author{
C. P. BRookes and H. D. LoXdale \\ Entomology Department, Rothamsted Experimental Station, Harpenden, Herts, AL5 2JQ, UK
}

\begin{abstract}
A simple Perspex and stainless steel device is described suitable for rapid, simultaneous homogenization of numbers (60) of small insects individually for electrophoresis. Since this device significantly decreases the time taken for preparation of samples (commonly a rate-limiting stage in electrophoretic studies), it may be of value to other workers in entomology and insect population genetics.
\end{abstract}

\section{Introduction}

In order to reduce sample preparation time of aphids for electrophoretic examination of enzyme markers, we designed and built a simple device which allows rapid homogenization of numerous individual specimens simultaneously. Previously (Loxdale et al., 1983; Loxdale et al., 1985), individual aphids were homogenized one at a time, using flame-sealed Pasteur pipettes, in $15 \mu \mathrm{l}$ homogenizing medium held within small polyethylene centrifuge tubes or in wells $3 \mathrm{~mm}$ in diameter and $8 \mathrm{~mm}$ deep drilled into the upper surface of a flat Perspex block. Our new device, a modification of the latter system, can be used to homogenize 60 aphids simultaneously. The labour-saving features of the device may be of interest to other entomologists and population geneticists engaged in electrophoretic studies of small insects (aphids, Drosophila, etc.).

\section{Specifications and use}

The homogenizer (Fig. 1) consists of two separate square blocks of Perspex of equal thickness $(13 \mathrm{~mm})$ but of slightly different length and breadth $(85 \times 85 \mathrm{~mm}$ and $100 \times 100 \mathrm{~mm})$, the larger basal block containing rows of vertical wells $(3 \mathrm{~mm}$ in diameter $\times 7 \mathrm{~mm}$ deep) into which fit stainless steel pins (ca. $1.25 \mathrm{~mm}$ in diameter $\times 11 \mathrm{~mm}$ exposed length $(24 \mathrm{~mm}$ total length)) protruding from the lower surface of the smaller, upper block. The wells (total number 60 ) are arranged in alternate rows of seven and eight with a centre-to-centre distance of $10 \mathrm{~mm}$, and have roughly concave bottoms as cut during drilling. The steel pins, which pass through the thickness of the upper block, are held firm with epoxy resin glue (Araldite); they have rounded lower ends and all fit exactly dead-centre with, and reach the bottom of, the wells when the two halves of the device are fitted together. Centreing of the pins in the holes is achieved by simultaneously drilling through the upper into the lower block with a drill $1.25 \mathrm{~mm}$ in diameter; the holes of the lower block are then expanded to the desired diameter using a larger drill. In order to locate both halves easily in the correct pin-hole orientation, the same corner of both blocks can be chamfered as shown in Fig. 1. 


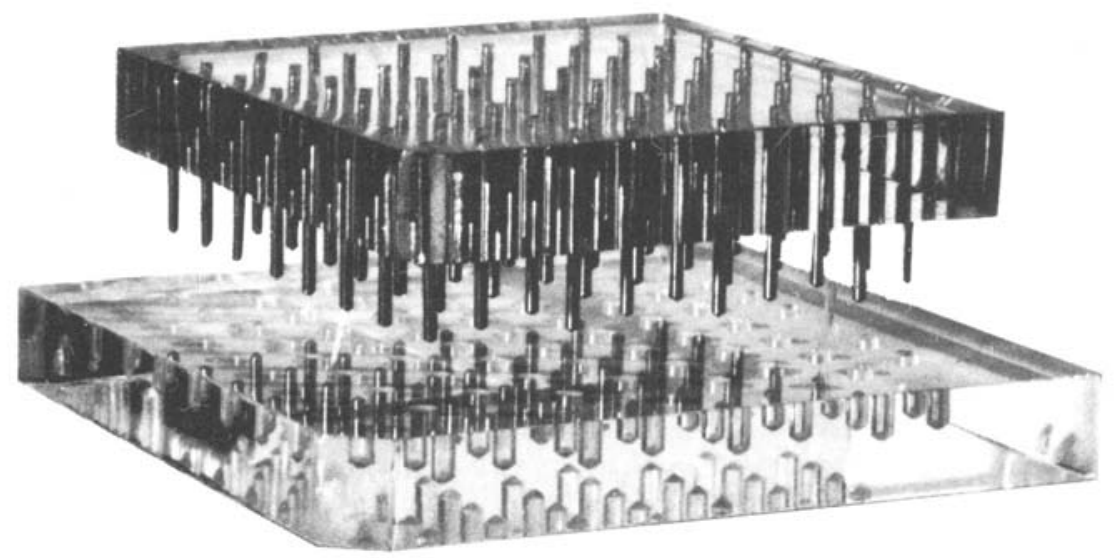

Fig. 1.-Device for simultaneously homogenizing small insects individually ( $\mathrm{ca} .60 \%$ actual size).

After adding from 15 up to $30 \mu$ l homogenizing medium and a sample specimen to each well, homogenization is effected by fitting the pins into the holes and displacing the blocks horizontally by hand in a circular motion relative to each other for several minutes.

\section{Discussion}

In electrophoretic studies, homogenization of large numbers of samples is both laborious and time-consuming and is often a major rate-limiting stage in the process. The device described homogenizes 60 specimens simultaneously and thus brings about a significant saving of time and effort. Larger models homogenizing double or even triple the number of specimens are feasible, although alignment of every pin and hole may then be a problem.

The present homogenizer was designed primarily for homogenizing aphids and, sometimes, their wasp parasitoids. However, the same principle could be applied, using larger pins and wells, to larger soft-bodied insects (say of the size of house-flies (Musca domestica L.)), the device perhaps being powered by an electric motor with eccentric drive.

\section{References}

Loxdale, H. D., Castañera, P. \& Brookes, C. P. (1983). Electrophoretic study of enzymes from cereal aphid populations. I. Electrophoretic techniques and staining systems for characterising isoenzymes from six species of cereal aphids (Hemiptera: Aphididae).-Bull. ent. Res. 73, $645-657$.

Loxdale, H. D., Tarr, I. J., Weber, C. P., Brookes, C. P., Digby, P. G. N. \& Castañera, P. (1985). Electrophoretic study of enzymes from cereal aphid populations. III. Spatial and temporal genetic variation of populations of Sitobion avenae (F.) (Hemiptera: Aphididae).Bull. ent. Res. 75, 121-141.

(Received 22 October 1984)

(C) Commonwealth Agricultural Bureaux, 1985 